\title{
Editorial: On Transition (in Physical Review Fluids leadership)
}

On February 1, 2021 the founding Lead Editors of Physical Review Fluids (PRFluids), John Kim and Gary Leal, retired and we had the privilege of assuming their roles. We take the opportunity of this transition to introduce ourselves, to highlight the journal's history and scope, and to inform the global fluid dynamics community of our goals. We also extend our sincere thanks to John and Gary for over twenty years of leadership, vision and advocacy on behalf of the fluid mechanics community.

We are in equal measures honored, humbled and excited to become Co-Lead Editors. Together, we bring knowledge of and experience with many facets of fluid dynamics. One of us (Eric) is an expert on theoretical fluid mechanics at low-Reynolds number, with a focus on complex and biological flows; the other (Beverley) brings a background in experiments and low-order modeling and has expertise in the areas of high-Reynolds-number turbulence and flow control. We have been educated and have conducted research in a variety of countries. As former Associate Editors, we know well the strengths of the journal and commit to investing our energy in expanding its impact. You can learn more about our backgrounds and those of our outstanding Editorial Team on the journal's Staff page.

In five short years, PRFluids has gone from a concept to a thriving reality: it is a home for innovative, exciting, and interdisciplinary developments across the field of fluid mechanics, and it is a journal run by scientists for scientists. This success results from APS' commitment, community support, and the immeasurable dedication of John and Gary. Since its inception, PRFluids has been devoted to publishing research that innovates and advances the fundamental understanding of flow physics. The journal not only embraces traditional topics in fluid mechanics, but it is also evolving to elevate and connect diverse newer areas such as geophysical and environmental flows, the fluid mechanics of energy, bio-related fluid dynamics, micro- and nanoscale flows, the fluid mechanics of complex fluids and soft materials, flow control, and applications of machine learning for physical insight and modeling. (The full scope of PRFluids can be found on the journal's About page.) We invite submission of important new results to our Letters section, which offers expedited time to publication. Our Editorial Team also brings attention to impactful research contributions through regular Editors' Suggestions and by proposing research for coverage in Physics Magazine. 
PRFluids benefits from a close connection with the APS Division of Fluid Dynamics (DFD), which is at the heart of the fluid mechanics and physics communities. The synergy between the two is reflected through the sponsorship of the annual François Frenkiel Award, which recognizes a noteworthy PRFluids paper by early career researchers, and through the "Fluids Next" Mini-Symposia proposed by the journal editors at the annual DFD meeting. PRFluids also publishes the winning entries to the DFD Gallery of Fluid Motion and commissions papers based on invited talks at the DFD meeting. This relationship with DFD is important to the journal, and one that we hope to strengthen even as we expand the journal's global ties.

As we begin our Lead Editorships, we will invest our energy in several fronts. We aim to continue the journal's work in upholding the highest scientific standards, providing leadership in technical publishing in fluid mechanics and publicizing emerging areas. In order to reach new research communities and the general public, we will make greater use of social media and multimedia activities, starting with a series of PRFluids Journal Club events (see more about the first one, held on April 12, 2021). We are also committed to promoting diversity and broadening participation in science, including that of early-career researchers, and we will work to make our editorial procedures even more transparent.

The journal's success rests on the community submitting novel fundamental research at the forefront of knowledge. We urge you to submit your most exciting work to PRFluids to strengthen existing areas, to cultivate new research directions, and to help the journal define the future of a healthy and innovative field.

Beverley McKeon and Eric Lauga

Co-Lead Editors

Physical Review Fluids

(Q) Published 21 April 2021

DOI: 10.1103/PhysRevFluids.6.040001 